\title{
Host-independent Growth of Bdellovibrio bacteriovorus in Microbial Extracts
}

\author{
By A. M. REINER* AND M. SHILO \\ Department of Microbiological Chemistry, \\ Hebrew University-Hadassah Medical School, Jerusalem, Israel
}

(Accepted for publication 23 September 1969)

\begin{abstract}
SUMMARY
Three Bdellovibrio bacteriovorus wild-type strains tested grew into long forms, up to 80 times their original lengths, when incubated in cell-free microbial extracts. This growth occurred both in extracts of organisms permissive and non-permissive for Bdellovibrio parasitic growth, but not in any other medium tested. Under certain osmotic conditions the long forms segmented into chains of cells. Some division of chains occurred. Only approximately $5 \%$ of the bdellovibrios grew into long forms. ${ }^{3} \mathrm{H}$-thymidine was incorporated into the long forms but not into short forms. A component of Pseudomonas aeruginosa extracts which supported growth of Bdellovibrios was macromolecular, heat stable and resistant to pronase, DNAse and RNAse.
\end{abstract}

\section{INTRODUCTION}

Bdellovibrio bacteriovorus is a bacterial parasite which multiplies inside susceptible bacterial host organisms. After growing inside the host, it segments into daughter cells which are released from the ghosted host (Scherf, DeVay \& Carol, I966; Starr \& Baigent, 1966; Shilo, 1969). The bdellovibrio-host system provides an experimentally accessible model for studying certain aspects of intracellular parasitism which are often more difficult to approach with parasites of animals and higher plants (Shilo, 1969). A problem encountered with all such systems is the difficulty of varying the environment in which the parasite grows. In an attempt to minimize this difficulty with bdellovibrios we have developed a new system that permits limited extracellular growth and division.

\section{METHODS}

Bacterial strains and growth. The Bdellovibrio bacteriovorus strain routinely used was a streptomycin-resistant isolate (spontaneous mutation) of strain I09. Bdellovibrios were grown in liquid culture using Escherichia coli K I 2 strain P 567 as host, according to the conditions of Varon \& Shilo (1968). Escherichia coli, Pseudomonas aeruginosa and Bacillus subtilis strain $68 \mathrm{~A}$ were grown on rotary shakers at $37^{\circ}$ in nutrient broth; B. cereus $\mathrm{T}$, at $30^{\circ}$ in nutrient broth; Micrococcus lysodeikticus, at $37^{\circ}$ on brain heart infusion; and Saccharomyces cerevisiae, at $30^{\circ}$ in nutrient broth $+2 \%(\mathrm{w} / \mathrm{v})$ glucose, adjusted to $\mathrm{pH} 6 \cdot 0$. Pseudomonas aeruginosa was isolated from a patient at Hadassah Hospital, Jerusalem. Other strains were from the collections of the Departments of Microbiological Chemistry and Bacteriology, Hebrew University, Hadassah Medical

* Present address: Department of Bacteriology and Immunology, University of California, Berkeley, California 94720, U.S.A. 
School. Bdellovibrio plaques were assayed on $E$. coli $\mathrm{P} 567$, by the method of Varon \& Shilo (1968).

Preparation of cell extracts. Cultures were harvested in late log phase (or for bdellovibrios, soon after host lysis was complete). Organisms were sedimented in a centrifuge, washed once and resuspended in a solution containing $0.3 \%(w / v)$ DifcoCasamino acids (vitamin free), $\mathrm{pH} 7.5$ (hereafter called 'amino acid buffer'). Bacteria were broken by sonic treatment for 5 to $10 \mathrm{~min}$. at 4 to $6 \mathrm{amps}$ in 10 to $30 \mathrm{ml}$. on a Bronson sonifier model no. 51 I 0 . For some experiments Pseudomonas aeruginosa organisms were lysed by incubation at $30^{\circ}(\mathrm{pH} 7 \cdot 8)$ for $20 \mathrm{~min}$. in a solution containing $30 \mu \mathrm{g}$. lysozyme $/ \mathrm{ml}$. and $4 \mathrm{mM}-E D T A$, after which they were incubated for $10 \mathrm{~min}$. at $20^{\circ}$ in a solution containing $20 \mu \mathrm{g}$. DNAse $/ \mathrm{ml}$. and $10 \mathrm{mM}-\mathrm{MgSO}_{4}$. Debris and most remaining intact cells were removed by centrifugation at $20,000 \mathrm{~g}$ for $\mathrm{I} 5 \mathrm{~min}$. Extracts were then filtered through HA filters (Millipore Corp., Bedford, Mass.) to remove any remaining intact organisms. For some experiments extracts were separated into supernatant and pellet fractions by centrifugation at $120,000 \mathrm{~g}$ for $2 \mathrm{hr}$ at $4^{\circ}$. In these cases the pellet was washed in amino acid buffer, recentrifuged as above and resuspended in amino acid buffer. Supernatant and pellet fractions were refiltered through HA filters. Extracts or fractions were then dialysed in tubing (No. 18/32, Scientific Instrument Centre, London, England) which had been sterilized by being autoclaved suspended from a capped glass tube into a flask containing the liquid to be dialysed against. Unless stated otherwise, 'bacterial extract' refers to an extract of $P$. aerugenosa prepared by sonication, filtered and dialysed overnight ( $\mathrm{I}: 200)$ against amino acid buffer. These extracts retained 50 to $90 \%$ of their 'activity' (see below) after storage up to I month at $4^{\circ}$.

Incubation mixture for induction of long forms. The standard incubation mixture contained $\mathrm{I} \cdot 5 \times 10^{9}$ bdellovibrios $/ \mathrm{ml}, 5 \mathrm{mg}$. Difco-Casamino acids (vitamin free), $\mathrm{pH} 7 \cdot 5 / \mathrm{ml}$. and bacterial extract or other material being tested for its ability to induce growth. Incubation was at $30^{\circ}$, with shaking, for the time stated. Bdellovibrios were prepared from cultures cooled to $4^{\circ}$ when lysis of Escherichia coli appeared by phase contrast microscopy to be complete. After o to $8 \mathrm{hr}$, cultures were centrifuged at $750 \mathrm{~g}$ for $2 \mathrm{~min}$. to remove any precipitate present in the growth medium, and then at $27,000 \mathrm{~g}$ for $20 \mathrm{~min}$. to pellet the bdellovibrios. These organisms were then resuspended in modified TM

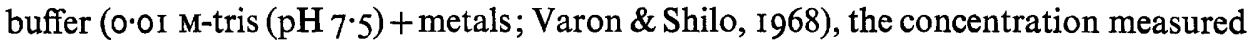
spectrophotometrically and a portion added to the incubation mixture as $\frac{1}{3}$ to $\frac{1}{2}$ the final volume. Bacterial extract was added to a final concentration of $\mathrm{I} \cdot 0 \mathrm{mg}$. protein $/ \mathrm{ml}$., unless otherwise stated. Protein determinations were by the Biuret method.

Thymidine-incorporation experiments. To measure thymidine incorporation into acid-precipitable material, thymidine-methyl ${ }^{3} \mathrm{H}$ (2 $\mathrm{c} / \mathrm{mm}$, Radiochemical Centre, Amersham, England) was added at the designated time to the standard incubation mixture just described, normally to final concentration $3 \mu \mathrm{c} . / \mathrm{ml}$. At the same time, non-labelled thymidine was added to final concentration $0.5 \times 10^{-4} \mathrm{M}$. At appropriate times, $50 \mu \mathrm{l}$. samples were removed and applied to paper discs (Whatman $3 \mathrm{MM}$ ). Discs were passed successively through three beakers containing cold $10 \%$ TCA and two beakers containing ethanol, and were dried. Radioactivity was measured in a scintillation counter. For the standard rate-of-incorporation assay, ${ }^{3} \mathbf{H}$-thymidine was added after the standard incubation mixture had shaken for I 2 to $13 \mathrm{hr}$. A $50 \mu \mathrm{l}$. sample was removed $2 \mathrm{hr}$ later and the acid precipitable counts determined as above. 
Microscopy. For determining the fraction of long forms in a Bdellovibrio population, cultures after $\mathrm{I} 3 \mathrm{hr}$ incubation were suspended in $0.05 \mathrm{M}-\mathrm{Na}$ azide plus $0 . \mathrm{I} \mathrm{M}-\mathrm{Na}$ acetate (pH 6.0) to stop motility and then examined by phase contrast in a PetroffHausser counter. Each examination included 450 to 500 organisms. Those organisms which were both noticeably fatter than, and at least $4 \times$ the length of, the normal small bdellovibrios present, were counted as long forms.

Materials. Nutrient broth, casein amino acids, yeast extract, tryptone and brain heart infusion were from Difco Laboratories, Detroit, Mich. RNAse, RNAse-free DNAse and alcohol dehydrogenase were from Worthington Biochemicals, Freehold, N.J. Pronase (grade B) was from Calbiochem, Los Angeles, Cal. Yeast RNA and calf thymus DNA were from Sigma Chemical Co., St. Louis, Mo.

\section{RESULTS}

\section{Bdellovibrio growth in host-free cell extracts}

When Bdellovibrio strain 109 was aerated at $30^{\circ}$ in the presence of dilute dialysed cell-free extracts of Pseudomonas aeruginosa, approximately $5 \%$ of the organisms grew into long forms. Morphological changes were first observed by phase contrast microscopy after 4 to $5 \mathrm{hr}$, at which time some of the bdellovibrios were fatter and slightly longer and had lost their motility. Within an hour, some fatter organisms were 3 to 4 times the length of most of the visible bdellovibrios, and were characteristically limp, bending and flopping on their shorter axis in response to random disturbances of the liquid. During the next 5 to $\mathrm{Io} \mathrm{hr}$, progressively longer forms were visible. Over $80 \%$ of these were clearly segmented into units approximately $0.4 \mu \times$ $0.9 \mu$ (Pl. I). Chains as long as I00 units appeared.

Partial division of chains less than 15 units long was observed occasionally. In these instances the intact chains appeared to be quivering. Single breaks occurred after some minutes, seemingly at random along the chain. Usually, additional breaks were observed at intervals of several minutes, and single units released swum out of the field. Plate I, fig. 3-4 shows chains as they appeared during division.

Growth of long forms also occurred in dialysed cell-free extracts of Escherichia coli, Micrococcus lysodeikticus, Saccharomyces cerevisiae and Bdellovibrio bacteriovorus strain Iog itself (final protein concentrations of I mg./ml.). These forms were indistinguishable by phase contrast microscopy from those of Plate $\mathrm{I}$. We verified that $M$. lysodeikticus and S. cerevisiae are not hosts for Bdellovibrio strain 109. Little or no attachment of bdellovibrios to these cells was observed by phase contrast microscopy. No plaques were formed on these strains, even when loops of bdellovibrios at $10^{\circ} / \mathrm{ml}$. were spotted on cell lawns. Extracellular growth of bdellovibrios did not occur in any of a variety of complex media tested (see below).

In addition to Bdellovibrio I09, two strains independently isolated in Jerusalem from sewage were tested for extracellular growth (strains GB and T28, isolated by M. Varon). In Pseudomonas aeruginosa extract, each grew into long forms which closely resembled those of Plate $\mathrm{I}$.

In each of the above instances, only a fraction of the Bdellovibrios grew into long forms. Standard incubation mixtures prepared on separate days were estimated to be $6 \cdot 2,3.9,5.3$ and $7.0 \%$ long forms (for standard conditions and estimation procedure, see Methods). We were unable to increase this fraction by varying extract con- 
centrations, Bdellovibrio concentrations, the species source of the extract or the Bdellovibrio strain. The length of time after host cell lysis that the bdellovibrios were harvested had little effect. Other instances of phenotypic variation in a genetically homogeneous Bdellovibrio population, involving attachment to hosts, have been reported (Varon \& Shilo, I968, I969a).

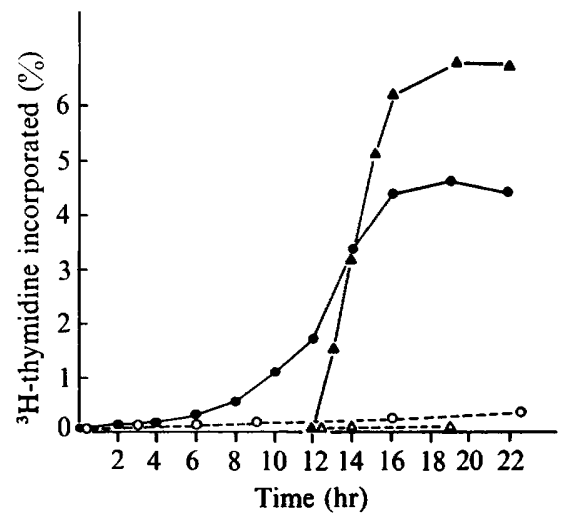

Fig. I

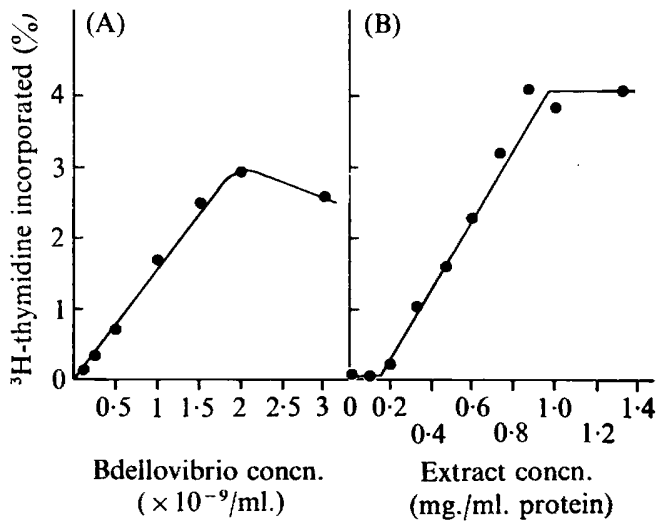

Fig. 2

Fig. I. Incorporation of ${ }^{8} \mathrm{H}$-thymidine during growth of long forms. Bdellovibrios were incubated with bacterial extract under standard conditions (see Methods) and $50 \mu l$. samples were removed at various times for determination of acid-precipitable counts. $\bullet,{ }^{3} \mathrm{H}$-thymidine added at $t=0 ; \Delta,{ }^{3} \mathrm{H}$-thymidine added at $t=\mathrm{I} 2 \mathrm{hr}$; open symbols, extract replaced by amino acid buffer in the incubation mixtures.

Fig. 2. Effect of bdellovibrios and bacterial extract concentrations on rate of thymidine incorporation. Standard rate of incorporation assays were performed (see Methods). (A) Bacterial extract concentration constant at $\mathrm{I} \bullet \mathrm{mg}$. protein $/ \mathrm{ml}$. (B) Bdellovibrio concentration constant at $\mathrm{I} \cdot 5 \times 10^{\circ} \mathrm{organisms} / \mathrm{ml}$.

\section{Thymidine incorporation during host-free Bdellovibrio growth}

Thymidine was incorporated into bdellovibrios during incubation in which long forms developed, but not under other host-free conditions. Upon incubation of Bdellovibrio, Pseudomonas extract and ${ }^{3} \mathrm{H}$-thymidine (see Methods) there was a lag period of several hours with little incorporation, followed by a much more rapid incorporation. If ${ }^{3} \mathrm{H}$-thymidine was added after the lag period, it was incorporated immediately (Fig. I). In the latter case, the rate of incorporation was found to vary linearily with both the concentration of cell extract and the Bdellovibrio concentration over the ranges shown (Fig. 2). Extracts of Micrococcus lysodeikticus stimulated incorporation to approximately the same extent. Separation of organisms according to size, on a sucrose gradient, showed that the label was distributed broadly among large forms, with $<2 \%$ incorporated into bdellovibrios of normal size (Fig. 3). Over $90 \%$ of the radioactivity incorporated was in DNAse-sensitive material.

On no occasion in this work did we observe long forms without thymidine incorporation or thymidine incorporation without long forms. Neither was ever observed without prior addition of cell extract or an extract fraction. None of the following nutrients induced long forms or thymidine incorporation: nutrient broth, yeast extract, tryptone, brain heart infusion (each at 29 and $35 \mathrm{mg}$. $/ \mathrm{ml}$. final concentrations); 
bovine serum albumin, haemoglobin, yeast RNA, calf thymus DNA, each at $0 \cdot 2$, I and $5 \mathrm{mg}$. $/ \mathrm{ml}$. final concentrations, in $4 \mathrm{mg}$. casein amino acids $/ \mathrm{ml}$. $\mathrm{pH} 7.5$; yeast RNA and calf thymus DNA degraded by RNAse and DNAse at 0.2 , I and $5 \mathrm{mg} . / \mathrm{ml}$., in $4 \mathrm{mg}$. casein amino acids $/ \mathrm{ml}$. $\mathrm{pH} 7 \cdot 5$.

In view of these results, we considered thymidine incorporation to be a useful supplement of microscopic examination as an indicator of the development of Bdellovibrio long forms. In the preliminary characterizations that follow, extract activity is quantitated in terms of the rate of ${ }^{3} \mathrm{H}$-thymidine incorporated into bdellovibrios under standard conditions (Methods). For each assay, growth at three or more extract concentrations was examined microscopically after I2 to $14 \mathrm{hr}$. In every instance this semi-quantitative examination was consistent with the results of the incorporation assay.

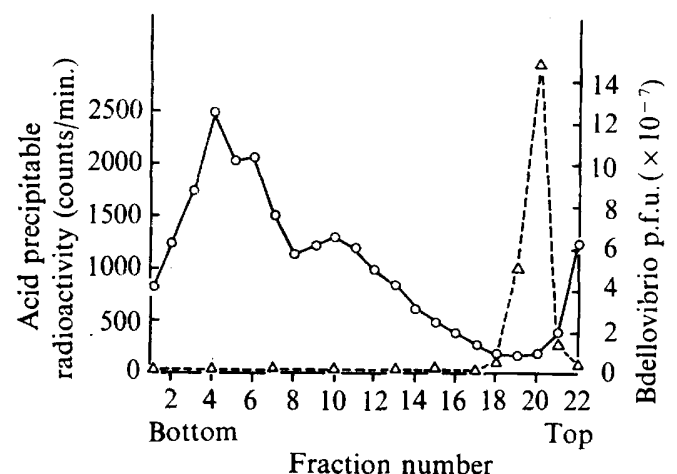

Fig. 3

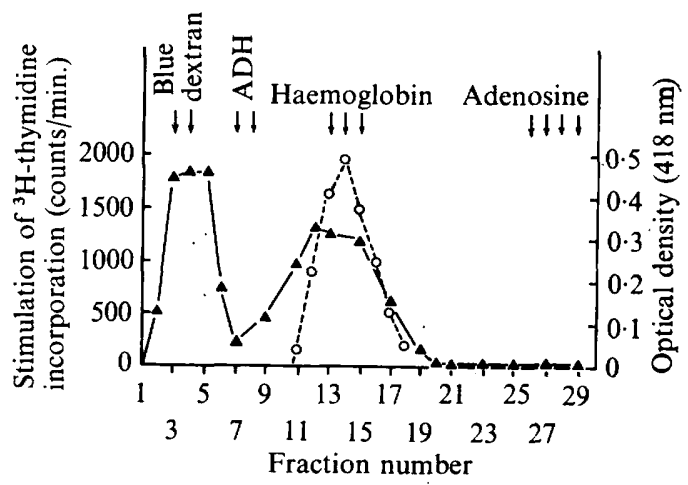

Fig. 4

Fig. 3. Sucrose gradient of Bdellovibrio organisms. ${ }^{3} \mathrm{H}$-thymidine was added to a standard mixture of bdellovibrios and bacterial extract which had incubated for $12 \mathrm{hr}$. Following $3 \mathrm{hr}$ additional incubation, $0.3 \mathrm{ml}$. of the mixture was layered on a $5 \mathrm{ml}$. gradient of 5 to $20 \%$ sucrose in amino acid buffer. The gradient revolved at 2000 r.p.m. for $10 \mathrm{~min}$. at $4^{\circ}$ in a clinical centrifuge. The tube was then punctured at the bottom and drops were collected. Recovery in the drops was $70 \%$ of the acid-precipitate counts applied to the gradient. $\bigcirc-O$, acid-precipitable counts; $\triangle-----\triangle$ Bdellovibrio plaque forming units.

Fig. 4. Sephadex G-I50 chromatography of supernatant fraction of bacterial extract. A $3 \mathrm{ml}$. sample, containing $40 \mathrm{mg}$. of bacterial protein and added molecular weight markers was applied to a $100 \mathrm{ml}$. column of Sephadex G-I $50\left(25 \mathrm{~cm} . \times 4 \mathrm{~cm} .{ }^{2}\right)$ equilibrated with $0.03 \mathrm{M}$ tris, $\mathrm{pH} 7.5$. Fractions of $2.2 \mathrm{ml}$. were collected and filter sterilized. Stimulation of ${ }^{3} \mathrm{H}$-thymidine incorporation into bdellovibrios was measured by the standard rate of incorporation assay (see Methods), using $0.15 \mathrm{ml}$. fraction aliquots in $0.3 \mathrm{ml}$. reaction mixtures. Incorporation of 1000 counts $/ \mathrm{min}$. is $1 \%$ of the ${ }^{3} \mathrm{H}$-thymidine added. ADH is yeast alcohol dehydrogenase, MW I $5 \mathrm{I}, 000$. $\Delta-\mathbf{\Delta}$, thymidine incorporation; $\mathrm{O}-\mathrm{A}_{--} \mathrm{O}$, optical density $(4 \mathrm{I} 8 \mathrm{~nm})$ due to haemoglobin marker.

\section{An active factor in cell extracts is macromolecular and heat stable}

A factor from cell extracts which induced long forms was non-dialysible. The activity in extracts of Pseudomonas aeruginosa, Escherichia coli, Micrococcus lysodeikticus, Saccharomyces cerevisiae and Bdellovibrio bacteriovorus increased 20 to $100 \%$ upon dialysis (based on rate of thymidine incorporation). Upon centrifugation of a dialysed sonicated extract of $P$. aeruginosa, at $120,000 \times g$ for $2 \mathrm{hr}, 40$ to $60 \%$ of the activity was recovered from the pellet and an approximately equal amount from the supernatant. (The same distribution between supernatant and pellet was obtained from extracts of $P$. aeruginosa prepared by lysozyme-EDTA). 
The supernatant material was fractionated by G-I50 Sephadex chromatography. All recovered activity, representing $65 \%$ of the total applied to the column, was in fractions of molecular weight $\geqslant 50,000$ (Fig. 4). No inhibitory material was detected in the fractions of lower molecular weight or the fractions between the two activity peaks. Long forms were induced by all fractions which stimulated thymidine incorporation (fractions 2 to 19), although the lengths were variable and, in the area between the peaks, considerably shorter than in the long forms induced by the unfractionated material. The other fractions did not induce long forms of any size. The same pattern of activity was obtained when the molecular weight markers were omitted.

The non-dialysible factor from extracts was heat stable. More then $90 \%$ of the activity from diluted dialysed Pseudomonas aeruginosa, Escherichia coli and Micrococcus lysodeikticus extracts, or the supernatant fractions, remained after boiling for $20 \mathrm{~min}$. When extracts were autoclaved or boiled at very high concentration, a heavy flocculent precipitate appeared, and 50 to $100 \%$ of the activity was lost.

The factor was stable to DNAse, RNAse and pronase. Dialysed Pseudomonas aeruginosa extracts were first diluted to $5 \mathrm{mg}$. protein $/ \mathrm{ml}$. in $0.02 \mathrm{M}$-tris $(\mathrm{pH} \mathrm{7.5)}$ and heated for $5 \mathrm{~min}$ at $98^{\circ}$. To test DNAse and RNAse, $\mathrm{MgSO}_{4}$ was added to Io $\mathrm{mM}$, the enzymes added each to $30 \mu \mathrm{g}$. $/ \mathrm{ml}$., and the solution incubated for $30 \mathrm{~min}$. at $25^{\circ}$. Full activity remained, both before and after dialysis. To test pronase, the enzyme (final concentration $100 \mu \mathrm{g} . / \mathrm{ml}$.) was added to the diluted heated extract, and the solution incubated at $45^{\circ}$. After $60 \mathrm{~min}$. the mixture was heated for $5 \mathrm{~min}$. at $98^{\circ}$ to inactivate the pronase, and was assayed. Full activity remained. (If an extract was incubated at $45^{\circ}$ without prior heating at $98^{\circ}, 30$ to $90 \%$ of the activity was lost; the loss of activity varied between extract preparations, but was essentially the same whether or not RNAse, DNAse or pronase was present.)

\section{An assay for division}

${ }^{3} \mathrm{H}$-thymidine was incorporated almost exclusively into long forms (Fig. 3). If division occurs, label should appear later in short forms, with a corresponding loss from long forms. Evidence of this was obtained by the direct filtration of long form cultures on cellulose ester (Millipore) filters. Long forms are retained on $\mathrm{I} \cdot 2 \mu$ (mean pore diameter) filters, while most short forms pass through. Fig. $5 \mathrm{~A}$ shows that after I 5 to $20 \mathrm{hr}$ of incubation label appeared in material which passed through $\mathrm{I} \cdot 2 \mu$ filters. The results were basically the same when addition of ${ }^{3} \mathrm{H}$-thymidine was delayed (Fig. 5B). (Levels of incorporation measured by $0.22 \mu$ filter retained-material, and by acid-precipitable material, were indistinguishable.)

To examine more closely the size distribution of the divided forms, a Bdellovibrio mixture labelled as in Fig. 5B was displayed on a sucrose gradient after I4 and $24 \mathrm{hr}$ incubation (Fig. 6). In the period of sedimentation of these gradients, the undivided long forms pelleted, so that only small forms were visible (compare Fig. 3). Figure 6 shows that after $14 \mathrm{hr}$ little or none of the acid-precipitable radioactivity was in the region corresponding to small organisms, while at a later time $50 \%$ of the label was in this region. The radioactivity peak was slightly ahead of the bulk of the bdellovibrio organisms probably because the newly divided bdellovibrios were more compact than the longer and thinner older organisms and therefore sedimented faster (see below). 


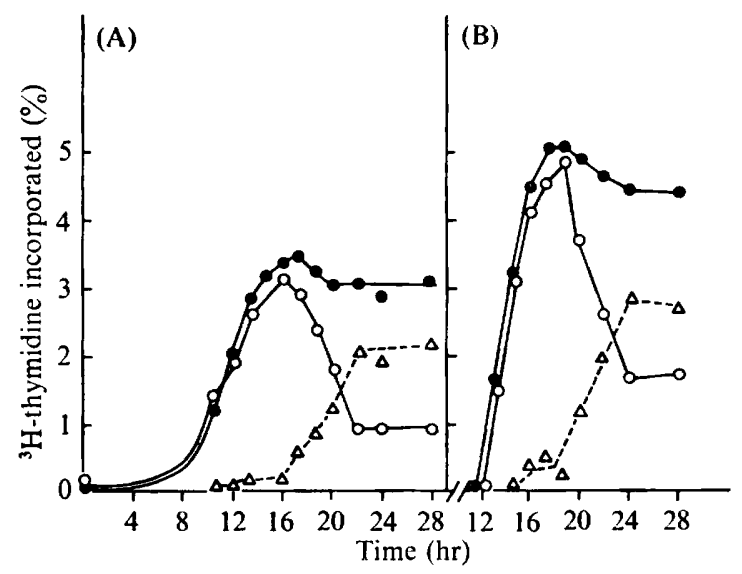

Fig. 5. Appearance of label in short forms. ${ }^{3} \mathrm{H}$-thymidine was added to a standard incubation mixture at $t=0$ (A) or $t=12 \mathrm{hr}$. (B). At various times $0.2 \mathrm{ml}$. samples were removed into $10 \mathrm{ml}$. of cold amino acid buffer and mixed for I min. Equal portions were filtered on $0.22 \mu$ and $\mathrm{I} \cdot 2 \mu$ filters. Each filter was washed with $50 \mathrm{ml}$. nutrient broth.

Material retained on $0.22 \mu$ filters, $\bigcirc-O$, material retained on $I \cdot 2 \mu$ filters; $\triangle-----\triangle$, material passing through $\mathrm{I} \cdot 2 \mu$ but retained on $0.22 \mu$ filters (by subtraction).

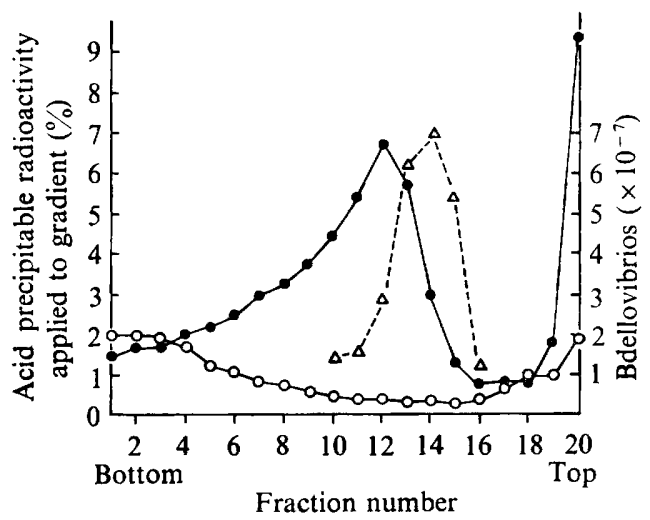

Fig. 6

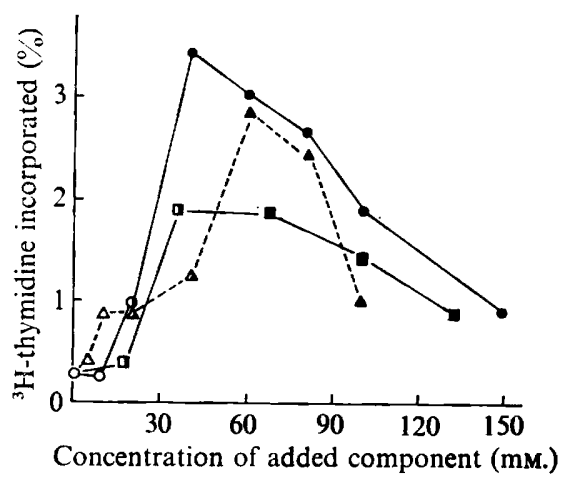

Fig. 7

Fig. 6. Sucrose gradients of Bdellovibrio organisms. ${ }^{\mathbf{3}} \mathrm{H}$-thymidine was added to a standard incubation mixture at $t=12 \mathrm{hr}$. At the specified times, $0.3 \mathrm{ml}$. of the mixture was layered on a sucrose gradient as in Fig. 3 and revolved at 2000 r.p.m. for $30 \mathrm{~min}$. The tubes were then punctured and drops were collected. $\mathrm{O}-\mathrm{O}$, Acid-precipitable counts of sample removed at $t=14 \mathrm{hr} ;-$, acid-precipitable counts of sample removed at $t=24$ hours; $\triangle-----\triangle$, Bdellovibrio concentration determined by Petroff-Hausser counter.

Fig. 7. Effect of osmolarity on morphology and thymidine incorporation. Standard rate of incorporation assays were performed, except that the usual amino acid concentration of $5 \mathrm{mg}$. $/ \mathrm{ml}$. was replaced by various amino acid, sucrose, or $\mathrm{NaCl}$ concentrations. After $13 \mathrm{hr}$ incubation, cultures were examined by phase contrast microscopy. acid added; $\triangle---\Delta$, sucrose added; $\square \longrightarrow \square, \mathrm{NaCl}$ added. Open symbols, coiled long forms; closed symbols, segmented, uncoiled forms; half closed symbols, intermediate or both forms. 
Two morphologically distinct long forms depending on osmotic conditions

In addition to the segmented long form already described, a tightly coiled nonsegmented long form was induced when amino acids were omitted from the standard incubation mixture (P1. 2, fig. 8-II). The effect was not due to nutrition, since the $\mathrm{NaCl}$ or sucrose concentrations also controlled which form appeared (Fig. 7). At intermediate concentrations, forms intermediate between tight-coil and segmented straight forms occurred. The addition of $\mathrm{NaCl}$, sucrose or amino acids after $\mathrm{I} 3 \mathrm{hr}$ growth of long forms in their absence did not induce a conversion of coiled to segmented forms, nor did it stimulate increased thymidine incorporation.

\section{Rich medium induces inclusion bodies in Bdellovibrio short forms}

In testing various rich media for growth of long forms, we frequently observed that prominent inclusion bodies, previously unreported in Bdellovibrio, were induced in the short forms. A reproducible procedure which we adopted was to incubate bdellovibrios at $30^{\circ}$ in cell-free dilute nutrient broth (DNB of Shilo \& Bruff, 1965) in which Pseudomonas aeruginosa had been heated for $30 \mathrm{~min}$ at $65^{\circ}$. Under these conditions, over $70 \%$ of the bdellovibrios developed one or more inclusion bodies within $4 \mathrm{hr}$ (P1. 2, fig. I2). Despite the small size of the bdellovibrios, these bodies were also visible by phase contrast microscopy.

\section{DISCUSSION}

Evidence had accumulated, from the enzymic content of Bdellovibrio (Simpson \& Robinson, I968) and its ability to grow equally well on live, heat-killed and u.v.-killed hosts (Varon \& Shilo, $1969 b$ ), that the role of the host bacteria in Bdellovibrio infection was limited to satisfying nutritional and/or physical requirements. The growth of bdellovibrios in bacterial extracts reported here further confirms this view. Since extracts of both hosts and non-hosts support growth, it is apparent that factors other than nutrition prevent bdellovibrios from parasitizing certain organisms. A physical barrier against attachment and/or penetration is the likely limitation in many cases. Chemical defences may be relevant as well, however. We noted in this connexion that dialysed and undialysed extracts of Bacillus cereus and B. subtilis induced few or no long forms, and inhibited the development of long forms when added to other extracts.

Osmotic as well as nutritional conditions affected extracellular growth in our system. At low osmolarity only non-segmenting forms occurred. On the other hand, low osmotic strength was excellent for motility (Varon \& Shilo, I968) and respiration (S. C. Rittenburg, unpublished data) of normal extracellular bdellovibrios. This may reflect the natural dichotomy encountered by bdellovibrios in their normal life cycle. Intracellular growth causes only limited leakage of host material to the extracellular environment (Drucker, I969), and so presumably occurs at high osmolarity. Motility and maintenance, on the other hand, occur in dilute extracellular environments.

Extracellular bdellovibrios demonstrate considerable metabolic activity (Simpson \& Robinson, 1968; Varon \& Shilo, 1969b). Differences were expected, however, between activities involving motility and maintenance, and those which involve growth. We looked for an activity specific enough to the growing forms to overshadow the corresponding activity in the majority population of the short forms. Experiments with radioactive uracil and leucine showed significant incorporation into both forms. Thymidine, however, was incorporated only into the long forms. Since growth of 
long forms in bacterial extracts occurred whether or not thymidine was added for an incorporation measurement, other sources of thymidine were available in the incubation mixtures. Nevertheless, we found that ${ }^{3} \mathrm{H}$-thymidine incorporation consistently was correlated with the amount of long forms.

We do not know to what extent the limited extracellular growth in our system is relevant to the intracellular parasitic growth of bdellovibrios. It could instead represent a facultative ability for extracellular growth, with characteristics and controls different from those of the intracellular cycle. There exist mutant Bdellovibrio strains which can multiply extracellularly in complex media with no requirement for a factor from bacterial extracts (Shilo \& Bruff, I965; Seidler \& Starr, 1968; Dietrich, Denny, Hashimoto \& Conti, 1969). The growing forms observed with such strains are significantly shorter than those in our system (M. Starr, personal communication). It is tempting to speculate that chains of up to I0o cells accumulate in our system because the bdellovibrios require a 'divide signal' which would normally occur intracellularly when nutrients were depleted, or when the pressure of the confining host cell wall was sensed. The osmotic requirement in our system also may suggest that growth is proceeding as if intracellularly. Additional studies are needed to clarify the relationship between the three demonstrable forms of Bdellovibrio growth (i.e., intracellular, extracellular in microbial extracts and extracellular by selected strains in complex media).

Intracellular parasites need access to the host materials. Many such parasites are permeable to molecules normally excluded from most organisms (Moulder, 1962; Hall \& Claus, 1963). A particularly striking case is that of Clamydaie psittaci, which changes to a more permeable form during the intracellular stage of its life cycle (Tamura \& Manire, r968; Moulder, 1968). Bdellovibrios may well undergo a similar change to a more permeable intracellular form. Since the extracellular long forms reported here may closely resemble intracellular bdellovibrios, it would be of interest to measure the relative permeability toward various molecules of the long and short forms. Such a permeability change early in intracellular development could exert direct control over many metabolic processes. Thus, DNA synthesis might begin when precursors which are normally excluded from the organism are free to enter. It is possible that thymidine uptake and subsequent incorporation into DNA in our system is an immediate consequence of a permeability change.

Elongation of bdellovibrios after lysis of the host culture has been observed previously (Varon \& Shilo, 1968). Typically, bdellovibrios, short and plump upon their release from the host, become thinner, rod-like and somewhat longer, sometimes doubling or tripling their original length. Burger, Drews \& Ladwig (1968) briefly reported a different observation, elongation of bdellovibrios into spiral forms in host cell extracts. In none of these cases do the lengths approach those observed in our system, and in no case was segmentation reported.

One of us (A. M. R.) received a grant from the B. de Rothschild Fund for the Advancement of Science and Technology, and an Advanced Studies Fellowship from the Hebrew University. These are gratefully acknowledged. 


\section{REFERENCES}

BURGER, A., DREWS, G. \& LADWIG, R. (I968). Wirkungskreis und Infektionscyclus eines neu isolierten Bdellovibrio bacteriovorus-Stammes. Arch. Mikrobiol. 6r, $26 \mathrm{I}$.

Dietrich, D. L., DeNNY, C. F., Hashimoto, T. \& ConTI, S. F. (I969). Isolation and characterization of host-independent endoparasitic mutant of Bdellovibrio bacteriovorus. Bact. Proc. p. 53.

DRUCKRR, I. (1969). Leakage of intracellular components from Escherichia coli B infected with Bdellovibrio bacteriovorus. M.Sc. Thesis, Hebrew Univeristy, Jerusalem.

HaLL, W. T. \& ClaUS, G. (I963). Ultrastructural studies on the blue-green algal symbiont in Cyanophora paradoxa Korschikoff. J. Cell Biol. 19, 55I.

MOULDER, J. W. (1962). The Biochemistry of Intracellular Parasitism. Chicago, Ill.: University of Chicago Press.

Moulder, J. W. (1968). The life and death of the psittacosis virus. Hospital Practice 3, 35.

SChERF, R. H., DEVAY, J. E. \& CAROL, T. W. (1966). Ultrastructure of host-parasite relationships involving reproduction of Bdellovibrio bacteriovorus in host bacteria. Phytopathology 6, 627 .

SEIDLER, R. J. \& STARR, M. P. (I 968 ). Isolation and characterization of host-independent strains of Bdellovibrio bacteriovorus. Bact. Proc p. 23.

SHILO, M. \& BRUFF, B. (1965). Lysis of Gram-negative bacteria by host-independent ectoparasitic Bdellovibrio bacteriovorus isolates. J. gen. Microbiol. 40, 317.

SHILO, M. (I969). Morphological and physiological aspects of the interaction of Bdellovibrio with host bacteria. Current Topics in Microbiol. and Immunol. 5o, in press.

Simpson, F. J. \& Robinson, J. (1968). Some energy-producing systems in Bdellovibrio bacteriovorus, strain 6-5s. Can. J. Biochem. 46, 865 .

STARR, M. P. \& BAIGENT, N. L. (I966). Parasitic interaction of Bdellovibrio bacteriovorus with other bacteria. J. Bact. 9I, 2006.

StOLP, H. \& STARR, M. P. (1963). Bdellovibrio bacteriovorus gen. et sp.n., a predatory, ectoparasitic, and bacteriolytic microorganism. Antonie van Leeuwenhoek J. Microbiol. Serol. 29, 217.

TAMURA, A. \& MANIRE, G. P. (1968). Effect of penicillin on the multiplication of Meningopneumonitis organisms (Chlamydia psittaci). J. Bact. 96, 875.

VARON, M. \& SHILO, M. (I968). Interaction of Bdellovibrio bacteriovorus and host bacteria. I. Kinetic studies of attachment and invasion of Escherichia coli в by Bdellovibrio bacteriovorus. J. Bact. 95, 744 .

VARON, M. \& SHLO, M. (1969a). Attachment of Bdellovibrio bacteriovorus to cell wall mutants of Salmonella spp. and Escherichia coli. J. Bact. 97, 977.

VARON, M. \& SHILO, M. (I969b). Interaction of Bdellovibrio bacteriovorus and host bacteria. II. Intracellular growth and development of Bdellovibrio bacteriovorus in liquid cultures. J. Bact. 99, 136 .

\section{EXPLANATION OF PLATES}

Figures 5-7 and II-I2 are electron micrographs taken by Dr Martin Kessel of this department. These specimens were prepared by negative staining by either I \% potassium phosphotungstate ( $\mathrm{pH} 7.0$ to 7.2 ) or I \% ammonium molybdate. Specimens were viewed in an AEI EM6B electron microscope operating at $60 \mathrm{kv}$.

Plate I

Bdellovibrio long forms grown on Pseudomonas aeruginosa extract. Photographs made after $16 \mathrm{hr}$ incubation at standard conditions. Small bdellovibrios are visible in background.

Fig. I-4. Phase contrast microscopy ( $\times$ I400).

Fig. 5. Electron microscopy $(\times 6000)$.

Fig. 6. Electron microscopy $(\times 7500)$.

Fig. 7. Electron microscopy $(\times 4500)$.

Plate 2

Fig. 8-II. Bdellovibrio long forms grown at low osmotic strength (see text). Photographs made after $16 \mathrm{hr}$ incubation.

Fig. 8-9. Typical highly coiled forms. Phase contrast microscopy ( $\times$ I 400 ).

Fig. 10. Less typical, less coiled form, showing coils more clearly. Phase contrast microscopy ( $x_{1400}$ ).

Fig. II. Electron micrograph $(\times 17,500)$. Highly coiled forms appear partly unravelled in electron microscope preparations.

Fig. 12. Bdellovibrio with inclusion bodies $(\times 20,000)$. 
Journal of General Microbiology, Vol. 59, No. 3

Plate I
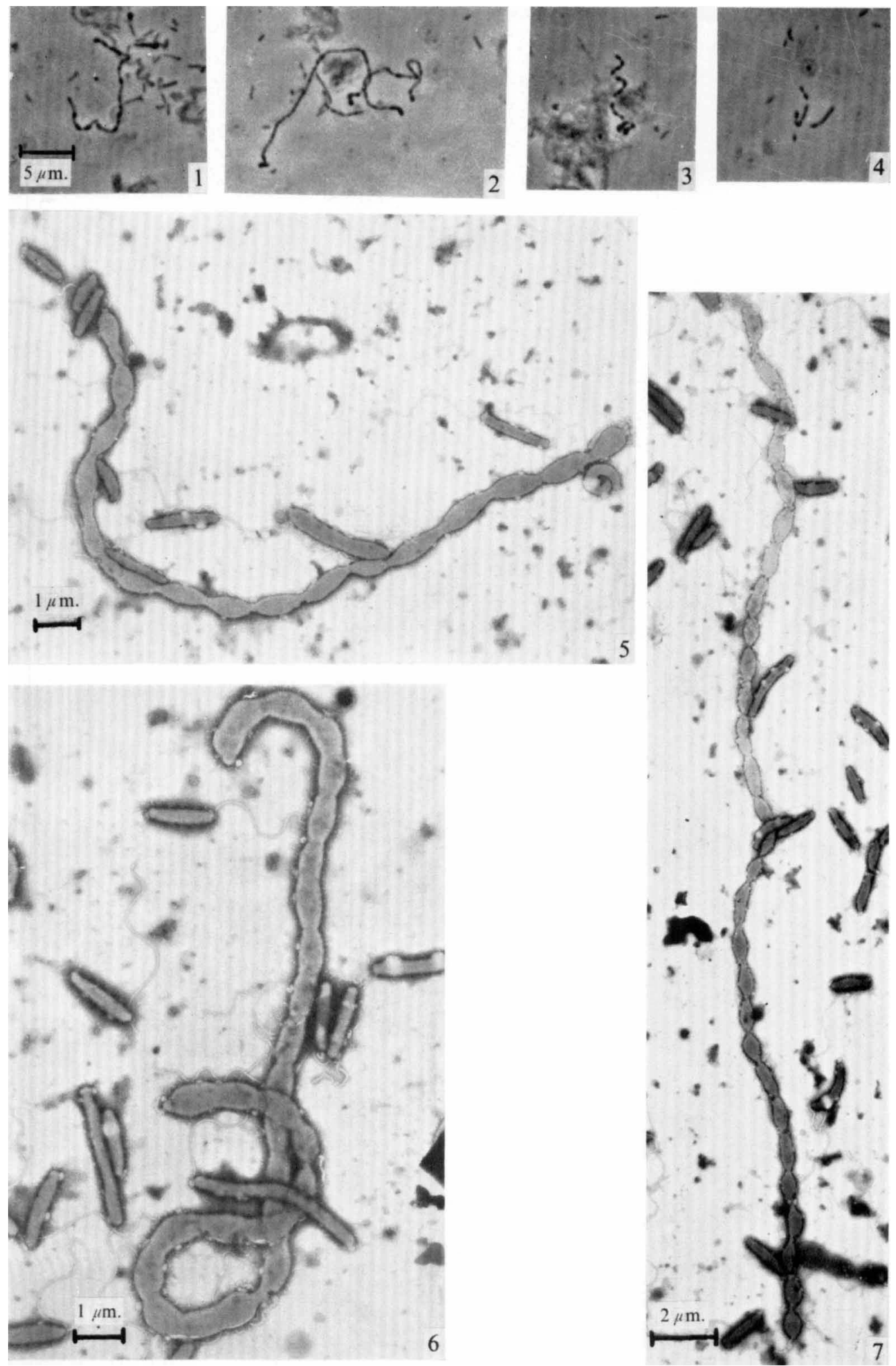

A. M. REINER AND M. SHILO

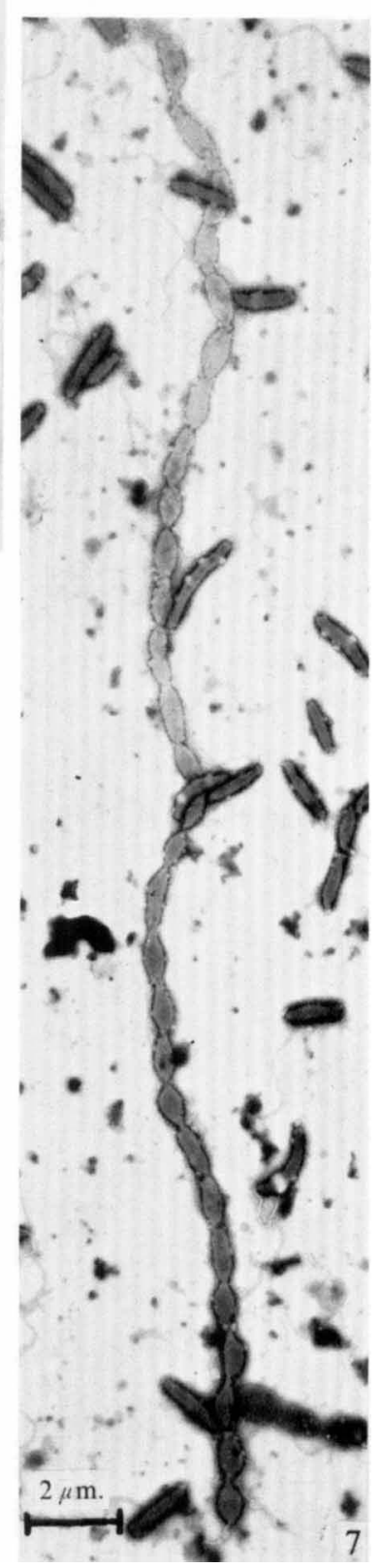

(Facing p. 4I $\mathrm{IO}$ ) 
Journal of General Microbiology, Vol. 59, No. 3

Plate 2
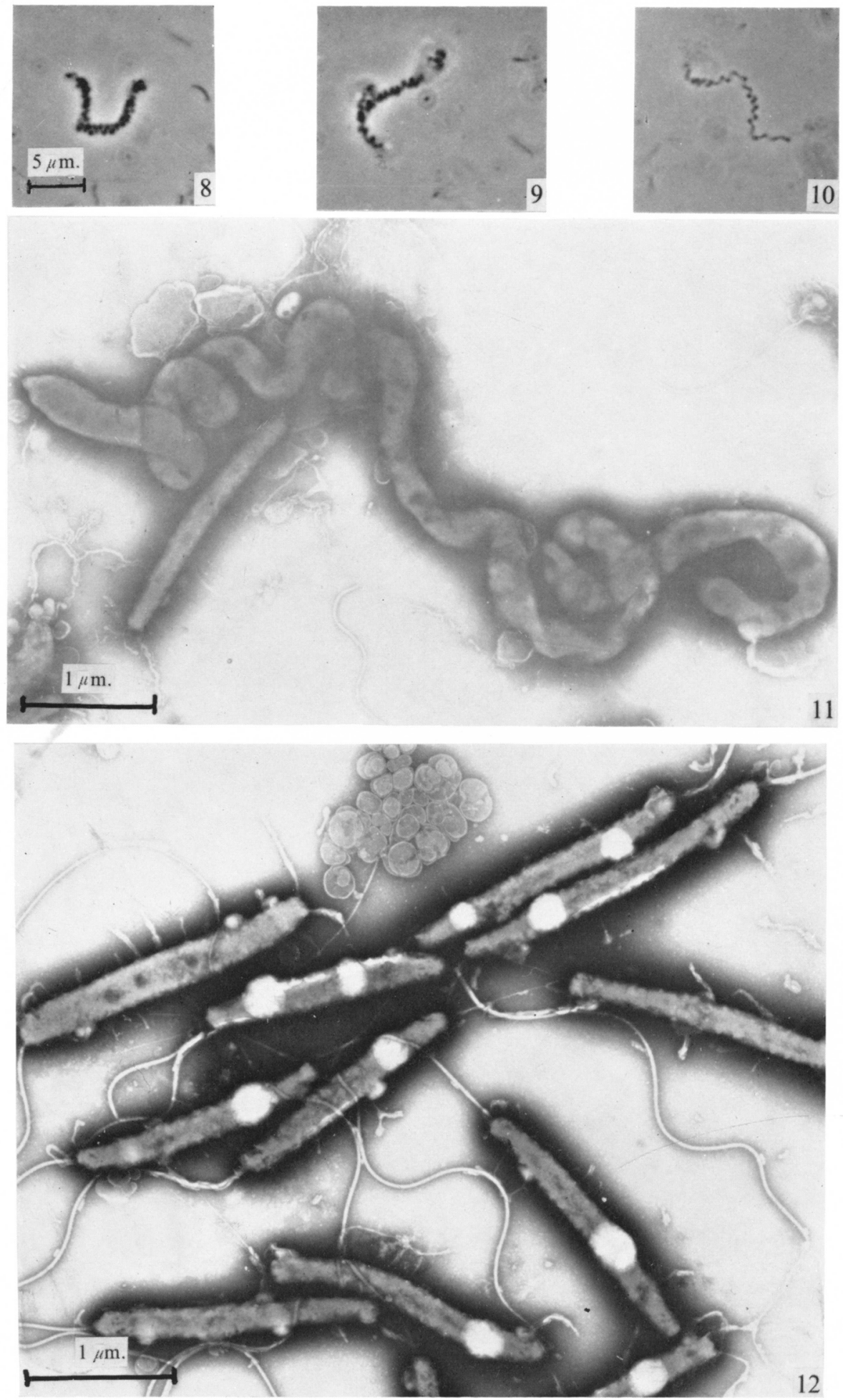

A. M. REINER AND M. SHILO 